\title{
CULTURA E CLIMA ORGANIZACIONAL: UM ESTUDO EM UMA ESCOLA PÚBLICA DE ENSINO MÉDIO DO ESTADO DE SÃO PAULO
}

\author{
Nattacia Rocha Duarte Ruani ${ }^{1}$, Maria Eliza Nogueira Oliveira ${ }^{2}$ \\ ${ }^{1}$ Faculdade de Presidente Prudente - FAPEPE, ${ }^{2}$ Universidade do Oeste Paulista - UNOESTE, Presidente Prudente, SP. E- \\ mail: nattduarte@yahoo.com.br.
}

\section{RESUMO}

O ambiente escolar deve colaborar para a formação integral do ser humano em vários aspectos, incluindo a sua capacidade de conviver nesta sociedade globalizada e multicultural e de atuar na construção e consolidação de espaços voltados ao atendimento dos direitos sociais e políticos. Em tese, o alcance desses objetivos se faz relevante compreender o clima e cultura organizacional da escola como elemento fundamental da gestão, pois esses elementos são um conjunto de forças latentes que determinam o comportamento, a maneira como se percebem o cotidiano, o modo de pensar e os valores individuais e coletivos do ambiente educacional. Todavia, o objetivo geral deste artigo é identificar e analisar a cultura e o clima de uma escola pública de ensino médio do Estado de São Paulo. Este trabalho assume a perspectiva que a cultura da escola é um elemento relevante no modo de organização do espaço escolar, interferindo na definição dos objetivos escolares e na atuação dos sujeitos que assumem a função de concretizá-los. Adotamos, a metodologia de caráter qualitativo, composta por dados coletados por meio de observações, entrevistas, questionários e análise documental.

Palavras-Chave: Cultura Organizacional da Escola. Clima Organizacional da Escola. Gestão Escolar. Escola. Ambiente.

\section{CULTURE AND ORGANIZATIONAL CLIMATE: A STUDY IN A PUBLIC SCHOOL OF MIDDLE SCHOOL OF THE STATE OF SÃO PAULO}

\begin{abstract}
The school environment should contribute to the integral formation of the human being in several aspects, including his capacity to live in this globalized and multicultural society and to act in the construction and consolidation of spaces aimed at the fulfillment of social and political rights. In thesis, the achievement of these objectives becomes relevant to understand the climate and organizational culture of the school as a fundamental element of the management, because these elements are a set of latent forces that determine the behavior, the way one perceives the everyday, the way of thinking And the individual and collective values of the educational environment. However, the general objective of this article is to identify and analyze the culture and climate of a public high school in the State of São Paulo. This work assumes the perspective that the school culture is a relevant element in the way school is organized, interfering in the definition of the school objectives and in the performance of the subjects that assume the function of concretizing them. We adopted the methodology of qualitative character, composed of data collected through observations, interviews, questionnaires and documentary analysis.
\end{abstract}

Keywords: Organizational Culture of the School. Organizational Climate of the School. School management. School. Environment. 


\section{INTRODUÇÃO}

A escola é uma instituição fundamental para o indivíduo e para a evolução da sociedade e da humanidade. Assim, o ambiente escolar, deve colaborar para o desenvolvimento integral dos seres humanos, estimulando e educando as crianças e os jovens à convivência e ao respeito mútuo. O desenvolvimento da cidadania requer o respeito universal aos direitos de igualdade entre todos os seres humanos, e também aos correspondentes deveres mútuos, perante a sociedade. (DESSEN; POLONIA; 2007)

É relevante compreender a cultura organizacional da escola como elemento fundamental da gestão, pois ela é uma poderosa e, muitas vezes, ignorada conjunto de forças latentes que determinam o comportamento, a maneira como se percebem as coisas, o modo de pensar e os valores individuais e coletivos. Assim, Schein (2007) ressalta que se faz importante compreender a cultura, pois as decisões tomadas sem consciência das forças culturais operantes podem ter consequências imprevistas e indesejáveis.

Deste modo, o objetivo geral deste artigo é identificar e analisar a cultura e o clima de uma escola pública de ensino médio do Estado de São Paulo. A problemática central de nossa pesquisa está sintetizada na seguinte questão: em que medida a cultura e o clima organizacional da escola intervém nos resultados do processo de ensino aprendizagem do aluno? Demarcada a área de estudos sobre cultura e clima organizacional, analisaremos a influência da cultura e clima organizacional da escola e como esses fenômenos têm impactado nos resultados de aprendizagem dos alunos aferidos por diversos recursos avaliativos.

\section{METODOLOGIA $^{1}$}

Adotamos, nesta pesquisa, uma metodologia de caráter qualitativo, composta por dados coletados por meio de observações, entrevistas, questionários e análise documental. Os questionários foram aplicados a alunos, professores, diretores e funcionários, e as entrevistas semiestruturadas a diretores e a uma amostra de professores e funcionários. As observações se concentram nos ambientes de planejamentos, convivência e sala de aula, das escolas em estudo.

\section{RESULTADOS}

Acreditamos não ser possível compreender a escola, apenas, a partir das propostas oficiais definidas por meio de legislação e políticas educacionais. Para conhecer a cultura e o clima organizacional da escola, é preciso se debruçar, de forma livre, sobre as ações que ocorrem no cotidiano escolar. Retomando o objetivo geral desta pesquisa que foi é identificar e analisar a cultura e o clima de uma escola pública de ensino médio do Estado de São Paulo.

Autonomia da escola. Percebe-se por meio das observações e argumentações durante as entrevistas e aplicação de questionários que a escola possui autonomia no que se se refere às decisões do cotidiano e à organização do espaço escolar. Em se tratando do currículo, os atores relataram que seguem o que já está estipulado pelas políticas curriculares, mas isso não os impedem de inserir novos conteúdos e discussões sempre que identificam necessários, ou até mesmo quando os alunos solicitam.

Liderança organizacional. Nóvoa $(1995$, p.26) destaca que a "coesão e qualidade de uma escola dependem em larga medida da existência de uma liderança organizacional efetiva e reconhecida". Assim, ao diagnosticar a cultura organizacional escolar do objeto em estudo, percebe-se que a figura da equipe gestora da escola, desenvolve um papel de liderança muito forte neste ambiente, sendo que o diálogo está fortemente presente neste espaço.

Articulação curricular e Otimização do tempo. Reconhece que através das entrevistas e observações que a otimização do tempo é realizada de forma eficaz. Professores e alunos estão focados em ensinar e aprender novos conteúdos a fim de se alinharem ao planejamento do

\footnotetext{
${ }^{1}$ O número do protocolo de aprovação do Comitê de Ética em Pesquisa é 58254016.5.0000.5515.
} 
currículo planejado e estabelecido pelas lideranças políticas. Nóvoa (1995) ressalta que a gestão do tempo deve respeitar os ritmos próprios internos da escola e de cada pessoa. No que se trata da articulação curricular, os assuntos abordados e ensinados na escola são coerentes às exigências dos alunos em relação a seus objetivos profissionais.

Estabilidade profissional e Formação profissional. Em se tratando da equipe gestora e professores constatou-se que todos possuem formação acadêmica em sua área de atuação, sendo que dois professores possuem mestrado. A equipe gestora ressaltou que a equipe de professores se interessam em fazer cursos de aperfeiçoamento e aplicam os conhecimentos adquiridos na prática, com o objetivo de se manterem atualizados às novas práticas. Como todos membros da equipe gestora e professores possuem formação em sua área de atuação, identificamos que os mesmos se sentem confortáveis em relação a sua estabilidade profissional.

Participação dos pais. Reconhece-se que a escola em estudo possui forte apoio dos pais, para o desenvolvimento de suas atividades. Faz parte da cultura escolar a presença e participação dos pais e ou responsáveis nas decisões e apoio à trajetória acadêmica destes alunos, desde a responsabilização em desenvolver as tarefas extraclasse, organização dos materiais didáticos necessários para o desenvolvimento das aulas; presença nas reuniões pedagógicas, assiduidade em conselhos de classe e escolares; participação em festas e confraternizações de datas comemorativas; reuniões com a coordenadora pedagógica para debater o desenvolvimento escolar; e orientações sobre o cumprimento de normas, regras e direitos presentes na escola. Nóvoa (1995, p.27) destaca que "as escolas com melhores resultados, normalmente, são aquelas que conseguem criar as condições propícias a uma colaboração das famílias na vida escolar" o autor ressalta que "os pais podem ajudar a motivar e a estimular os filhos, associando-se aos esforços dos profissionais de ensino".

Reconhecimento público e Apoio das autoridades. A imagem pública que a escola possui, é positiva. Tanto pelos seus membros internos sendo eles funcionários, professores, equipe gestora, alunos e pais ou responsáveis quanto seus membros externos. Nos questionários e observações realizadas, seus membros internos se manifestaram de forma favorável e confiante em relação a serem valorizados e reconhecidos por atuarem neste espaço escolar. A escola é reconhecida por ser referência em qualidade no ensino e de alcançar bons resultados quando se trata de avaliações em larga escala.

Estas características foram estabelecidas por Nóvoa (1995), como esboço do retrato de uma escola eficaz, na qual a cultura organizacional analisada nesta dissertação possibilita a investigação e consistência teórica e conceitual. $O$ trabalho desenvolvido permitiu identificar que a cultura e o clima que permeiam esta escola classificam-se como "cultura forte e aberta", na qual os membros analisados partilham dos mesmos objetivos e elementos que constituem a cultura e compartilham da influência entre pais, professores, alunos e gestores, para o desenvolvimento dos objetivos escolares, interagindo com o ambiente externo da escola com flexibilidade, adaptabilidade, tendo a comunicação de maneira transversal, alavancando as interações formais e não-formais entre os membros da escola e pontuadas pelo respeito.

\section{DISCUSSÃO}

O desenvolvimento do tema "cultura e clima organizacional da escola" pautou-se em estudos da Administração que se iniciaram em meados da década de 1980. Esses estudos foram motivados pela influência política, social e econômica praticada sobre as escolas, que impuseram a elas a urgente adaptação aos modelos de administração gerenciais e às demandas do mercado de trabalho. Apesar da crítica que se tem desenvolvido a respeito das limitações de administrar a escola nos modelos gerenciais/empresariais, dadas as suas especificidades, os estudos em cultura e clima organizacional permitiram a emergência de um movimento investigativo que priorizasse o 
estudo das dimensões culturais da escola de modo a permitir uma compreensão mais ampla de seu modo de funcionamento. (FÉLIX, 1984; PARO, 1986; TORRES, 2007).

No Brasil, em finais da década de 1970, a escola como objeto de estudo ganha destaque e passa a cooperar com um crescente processo de responsabilização da gestão escolar pelos problemas da qualidade do ensino público. Este desafio motivou análises e estudos voltados à compreensão das formas de funcionamento da unidade escolar e os determinantes históricos de sua existência. Emerge, deste contexto, a necessidade de compreender a cultura organizacional da escola de modo que esta compreensão seja utilizada como ferramenta no processo de constituição do espaço escolar, expondo sua organização, cotidiano e funcionamento (TEIXEIRA, 2000).

Sarmento (1994, p.95) postula que:

Relativamente às escolas, o conceito de cultura organizacional é decisivo para a sua compreensão [...]. A cultura organizacional das escolas é mesmo a única variável que permite entender como se realiza a unidade organizacional, dada a fragilidade das suas diversas articulações: são os símbolos e os mitos, de uma maneira geral processos partilhados de significação que garantem às escolas não apenas credibilidade e legitimação[...] mas uma ideia de unidade, que as permita diferenciar de outras organizações sociais e, a nível de cada estabelecimento de ensino, de outras escolas [...].

Nesta óptica, salientamos que as organizações escolares norteiam-se tanto pelas diretrizes e valores internos quanto pela política educacional estipulada pelos governos em atuação responsáveis pela consolidação de uma "cultura maior". Ressaltamos que as escolas também desenvolvem suas próprias práticas, proporcionando um ambiente dinâmico, flexível, em que se recriam diversos tipos de culturas, constituídas por vários elementos, que influenciam sua configuração interna e interagem com os aspectos de ordem histórica, ideológica, sociológica e psicológica (TEIXEIRA, 2002). Em nossa perspectiva, as escolas diferenciam-se entre si, pois são capazes de criar suas próprias identidades, por meio de negociações que vivenciam em diferentes situações e sistemas de ações.

No entanto, é importante destacar que as temáticas cultura e clima organizacional não estão desligadas dos traços culturais presentes na cultura brasileira, como o centralismo e o formalismo que têm conduzido a administração no ensino, apesar do forte movimento de descentralização administrativa que ocorreu com bastante força nos anos finais do século XX. (DIAS, apud VIEIRA, 2007)

\section{CONCLUSÃO}

Acreditamos que o ambiente escolar deve colaborar para a formação integral do ser humano em vários aspectos, incluindo a sua capacidade de conviver nesta sociedade globalizada e multicultural e de atuar na construção e consolidação de espaços voltados ao atendimento dos direitos sociais e políticos. Em tese, o alcance desse objetivo passaria pela mudança no clima e na cultura das escolas e, em contrapartida, permitiriam melhorias nos resultados de aprendizagem dos alunos. Todavia, vê-se que os objetivos voltados à melhoria de desempenho em testes padronizados, nem sempre coadunam com os objetivos da formação integral sinalizados anteriormente.

Destacamos que há uma aproximação entre o clima e a cultura organizacional da escola, uma vez que fazem parte do mesmo fenômeno complexo, interagindo-se. A diferença entre esses fenômenos reside na compreensão de que a cultura organizacional da escola é algo construído ao longo do tempo, cuja mudança ocorre de forma mais lenta, enquanto o clima retrata situações 
temporárias, que estão sujeitas a mudanças, por ser influenciado diretamente pelas práticas de gestão em curso. O processo de mudança da cultura organizacional ocorre seguindo os mesmos princípios que encaminham sua formação. Esta mudança não ocorre de forma rápida e impositiva, mas longa, processual e interativa, permitindo aos sujeitos que atuam no espaço assumir novos valores, crenças, pressupostos, entre outros elementos que constituem a cultura organizacional de qualquer instituição (LÜCK, 2010).

\section{REFERÊNCIAS}

DESSEN, Maria Auxiliadora; POLONIA, Ana da Costa. A Família e a Escola como Contextos de Desenvolvimento Humano. Paidéia, 2007.

FÉLIX, Maria de Fátima Costa. Administração Escolar: problema educativo ou empresarial? SP, Cortez, 1984.

LÜCK, Heloísa. Gestão da Cultura e do Clima Organizacional da Escola. Petrópolis: Vozes, 2010.

NÓVOA, Antônio. Para uma análise das instituições escolares. In NÓVOA, Antônio. (orgs). As Organizações Escolares em Análise. Lisboa: Dom Quixote, 1995.

PARO, Vitor Henrique. Administração escolar: introdução crítica. São Paulo: Cortez: Autores Associados, 1986.

SCHEIN, Edgar H. Guia de Sobrevivência da Cultura Corporativa; tradução Monica Braga. 2ª ed. Rio de Janeiro: José Olympio, 2007.

TEIXEIRA, Lucia Helena Gonçalves. Cultura Organizacional da Escola: uma perspectiva e análise e conhecimento da unidade escolar. Associação Nacional de Política e Administração da educação. RBPAE: Porto Alegre, v.16, n1, jan/jun, (2000).

TEIXEIRA, Lucia Helena Gonçalves. Cultura organizacional e o projeto de mudança em escolas públicas. Campinas: ANPAE, 2002.

TORRES, Leonor Lima. Cultura Organizacional Escolar: Apogeu investigativo no quadro de emergência das políticas neoliberais. Rev. Educ. Soc., Campinas, vol.28, n.98, p.151-179, jan./abr. 2007. Disponível em: http://www.cedes.unicamp.br

SARMENTO, Manuel Jacinto. A vez e a voz dos professores. Contribuindo para o estudo da cultura organizacional da escola primária. Porto: Porto, 1994.

VIEIRA, Almir Martins. Cultura organizacional em instituições de ensino: mapeamento e análise descritivo -interpretativa da produção acadêmica (1990-2005). Tese em Educação, Universidade Estadual Paulista - UNESP, Marília, 2007. 